\title{
Creatinine, total cysteine and uric acid are associated with serum retinol in patients with cardiovascular disease
}

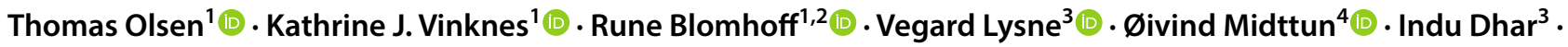

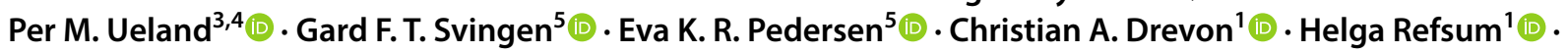 \\ Ottar K. Nygård ${ }^{3,5,6}$ (1)
}

Received: 17 March 2019 / Accepted: 30 August 2019 / Published online: 9 September 2019

(c) The Author(s) 2019

\begin{abstract}
Purpose We hypothesized that biomarkers and dietary factors related to cardiovascular disease risk were associated with serum retinol and evaluated these potential associations in patients with suspected coronary artery disease (CAD).

Methods We used cross-sectional data from 4116 patients hospitalised for suspected CAD. Dietary data were obtained from a subgroup of 1962 patients using a food frequency questionnaire. Potential biomarkers and dietary factors were explored using linear regression modelling adjusted for age and sex. Regression coefficients and corresponding confidence intervals (CI) are given as $\%$ change in serum retinol per unit change in the predictors. Analyses were performed in the total population and in strata of serum retinol tertiles.

Results In age- and sex-adjusted models, serum creatinine (standardized $\beta: 0.38,95 \%$ CI $[0.35,0.42]$ ), plasma total cysteine $(0.26,[0.23,0.29])$, serum uric acid $(0.30,[0.26,0.33])$ and plasma neopterin $(0.22,[0.18,0.25])$ were positively associated, whereas plasma serine $(-0.15,[-0.18,-0.12])$ and serum C-reactive protein $(-0.15,[-0.18,-0.12])$ were inversely associated with serum retinol. When we included the significant biomarkers in a multivariate model, the model explained $33 \%$ of the variability $\left(R^{2}=0.33\right)$ in serum retinol. The results were similar in the lower and upper tertiles of serum retinol. Weak or no associations were observed for dietary factors.

Conclusions In patients with suspected CAD, concentrations of creatinine, cysteine and uric acid were positively associated with serum retinol. Future studies should assess whether retinol concentrations are influenced by metabolic alterations in patients at risk of cardiovascular disease.
\end{abstract}

Keywords Retinol $\cdot$ Vitamin A $\cdot$ Cardiovascular disease $\cdot$ Creatinine $\cdot$ Cysteine $\cdot$ Uric acid

Thomas Olsen

thomas.olsen@medisin.uio.no

1 Department of Nutrition, Institute of Basic Medical Sciences, Faculty of Medicine, University of Oslo, Domus Medica, Sognsvannsveien 9, 0372 Oslo, Norway

2 Department of Clinical Service, Division of Cancer Medicine, Oslo University Hospital, Forskningsveien 2A, 0372 Oslo, Norway

3 Centre for Nutrition, Department of Clinical Science, University of Bergen, Haukelandsbakken, 5009 Bergen, Norway

4 Bevital AS, Jonas Lies vei 87, 5021 Bergen, Norway

5 Department of Heart Disease, Haukeland University Hospital, Jonas Lies vei 65, 5021 Bergen, Norway

6 Mohn Nutrition Research Laboratory, Department of Clinical Science, University of Bergen, Haukelandsbakken, 5009 Bergen, Norway

\section{Introduction}

Vitamin A is an essential, fat-soluble micronutrient that refers to all-trans retinol and its bioactive metabolites retinaldehyde, retinoic acid (RA) as well as retinyl ester and provitamin A carotenoids [1]. Following dietary intake from foods of plant and/or animal origin, retinol is transported as retinyl esters with triacylglycerol-rich chylomicrons to the liver where it can either be stored in hepatic stellate cells or exported to peripheral tissue bound to retinol-binding protein 4 (RBP4) and transthyretin. Retinol is then converted to RA in target tissues where it functions as a ligand for nuclear RA receptors with several target genes involved in growth and differentiation, metabolism of macronutrients [2], and the immune system [3]. 
We have recently reported that elevated serum retinol potentiates the risk of incident acute myocardial infarctions associated with traditional risk markers in subjects hospitalised for suspected coronary artery disease, including lipids and total homocysteine $[4,5]$. The circulating retinol concentrations in these patients exceed those reported from other cohorts [6-9], and retinol concentrations above clinical reference ranges have been associated with the metabolic syndrome [10] and cardiovascular disease (CVD) [11]. In addition, plasma concentrations of RBP4, which circulates with retinol in a nearly 1:1 manner, were elevated in conditions characterized by metabolic dysfunction such as diabetes type 2 [12], obesity [13] and atherosclerosis [14].

In spite of these recent observations, biomarkers associated with circulating retinol concentrations have not been well characterized in populations with CVD. Although early findings suggest that serum retinol is under tight homeostatic control except during conditions of deficiency or extreme excess [15], recent reports suggest that patients with chronic kidney disease have higher [16], whereas inflammation may reduce [17] serum retinol. Thus, the aim of this exploratory cross-sectional study was to identify biomarkers and dietary factors associated with serum retinol in a large cohort of patients with suspected or established CVD. Our focus was primarily on biomarkers relevant for CVD risk including circulating lipid parameters, homocysteine and inflammatory markers, as well as dietary factors and kidney function. Analyses were conducted for the total population and following stratification of patients according to tertiles of serum retinol.

\section{Methods}

\section{Study design}

The study population has been described extensively elsewhere [18]. Briefly, 4164 patients were initially included in this study. All patients were recruited upon planned angiography for suspected stable angina pectoris at Haukeland $(n=3413)$ and Stavanger $(n=751)$ University Hospitals, Norway and $61.8 \%(n=2573)$ were enrolled in the Western Norway B-vitamin Intervention Trial (WENBIT) (clinicaltrials.gov: NCT00354081) [19]. The main aim of the WENBIT was to address the effect of homocysteinelowering therapies with B-vitamins on a composite outcome consisting of all-cause death, nonfatal acute myocardial infarction, acute hospitalization for unstable stable angina pectoris and nonfatal thromboembolic stroke. Data were collected between 2000 and 2004. Patients with missing data on serum retinol $(n=46)$ and with extremely low $(<0.8 \mu \mathrm{mol} / \mathrm{L})(n=1)$ or high $(>9.0 \mu \mathrm{mol} / \mathrm{L})(n=1)$ concentrations of retinol were excluded from the study, yielding a total of 4116 eligible patients for analysis. Informed consent, ethical approval, and necessary permissions from the Norwegian Medicines Agency and the Norwegian Data Inspectorate were obtained. The study was carried out according to the Declaration of Helsinki.

\section{Baseline data, biochemical analyses and food frequency questionnaire}

Acquisition of clinical and diagnostic data including information on the presence and extent of coronary artery stenosis as determined by coronary angiography, body composition and smoking habits have been described in detail previously [18]. In addition, mostly non-fasting blood samples $(80 \%)$ were collected at baseline and serum samples were stored at $-80^{\circ} \mathrm{C}$ until analysis. Plasma concentrations of methionine, total homocysteine, cystathionine and cysteine were analysed using gas chromatography-mass spectrometry [20,21], whereas serum all-trans retinol [22], creatinine [23] and plasma neopterin [24] were measured by high-performance liquid chromatography/tandem mass spectrometry. Kynurenine, tryptophan, 4-pyridoxic acid (PA), pyridoxal (PL) and pyridoxal5-phosphate (PLP) were measured by liquid chromatography/tandem mass spectrometry [24]. Kynurenine to tryptophan ratio (KTR) and the PA-ratio (PAr; PA/PL + PLP) were calculated, and both have been proposed as markers of inflammation [25, 26]. All of the above measurements were performed in collaboration with Bevital AS, a company specializing in the assessment of biomarkers related to nutritional status and inflammation (http://www.bevit al.no). Concentrations of fibrinogen, total cholesterol, apolipoprotein A1 and B, C-reactive protein (CRP), and dietary vitamin A intake were measured as described previously [4, 18, 27]. Serum uric acid measurements were part of the routine laboratory analytical panel [18].

Baseline dietary data were obtained from 2068 WENBIT participants from a 169 -items food frequency questionnaire (FFQ). After exclusion due to noncompletion of the FFQ, very high $(>15,000 \mathrm{~kJ} /$ day for females, $>17,500 \mathrm{~kJ} /$ day for males) or very low energy intake ( $<3000 \mathrm{~kJ} /$ day for females, $3500 \mathrm{~kJ} /$ day for males), 1962 patients were eligible for analysis. The development of the FFQ has been described elsewhere and has been validated for total energy intake and several nutrients [28-30]. Frequency of consumption and measures were converted by a conversion system developed by the Department of Nutrition, University of Oslo (Kostberegningssystem, version 3.2; University of Oslo). Vitamin A intake is given as retinol activity equivalents (RAE), and conversion values are based on the official Norwegian Food Table. 


\section{Statistical analysis}

The majority of the continuous data were not normally distributed. Log-transformed continuous variables are, therefore, presented as geometric means (gM) (geometric standard deviations [gSD]). Intake data on macronutrients are presented as the proportion of total energy intake (E \%), and food items as densities ( $\mathrm{g} / 1000 \mathrm{kcal})$. Vitamin A intake is given as RAE/1000 kcal. Categorical variables are given as $n(\%)$. Baseline characteristics are given for the total population.

We used ordinary least squares regression to evaluate individual predictors of log-transformed concentrations of serum retinol. All models were adjusted for age (continuous) and sex (categorical) unless otherwise specified, and plasma/serum predictors were log-transformed. Models including dietary intakes were additionally adjusted for energy intake. No data transformation was applied to the dietary data. Estimates are reported as standardized $\beta$ which indicate the standard deviation change in serum retinol per standard deviation change in the exposure variable, which is equivalent to the partial correlation coefficient.

For the sake of interpretability, we also report unstandardized $\beta \mathrm{s}$ (95\% confidence interval). In models where the exposure and outcomes are log-transformed, the $\beta$ s represent the $\%$ change in serum retinol indicated by $1 \%$ increase in the exposure variable, respectively. These were subsequently multiplied by ten, and thus represent the $\%$ change in serum retinol indicated by $10 \%$ increase in the exposure variable. For models including dietary data, the $\beta$ represents the $\%$ change in serum retinol indicated by $1 \mathrm{E} \%$ (macronutrients), $50 \mathrm{~g} / 1000 \mathrm{kcal}$ (food groups) or $200 \mathrm{RAE} / 1000 \mathrm{kcal}$. Additionally, we calculated the adjusted $R^{2}$ to obtain the variance explained by each model. The linearity of associations was visualized using generalized additive model (GAM) plots. After Bonferroni adjustment, $p<0.001$ was considered statistically significant. Finally, all variables associated with serum retinol after Bonferroni adjustment were included in a single model and the adjusted $R^{2}$ was calculated. Statistical analyses were performed using $\mathrm{R}$ version 3.6.1 and packages included in the "tidyverse" as well as "sjstats". All figures were made with the "ggplot2" package.

\section{Results}

\section{Baseline characteristics}

Baseline characteristics and dietary intake for the total population are presented in Table 1 and 2. Serum concentrations of retinol ranged from 1.02 to $7.65 \mu \mathrm{mol} / \mathrm{L}$, and the $\mathrm{gM}(\mathrm{gSD})$ was $2.84(1.26) \mu \mathrm{mol} / \mathrm{L}$. The cohort consisted of $71.9 \%$ men, and $\mathrm{gM}(\mathrm{gSD})$ age was 60.8 (1.19) years,
Table 1 Baseline characteristics of the total population $(n=4116)$

\begin{tabular}{|c|c|}
\hline Retinol, $\mu \mathrm{mol} / \mathrm{L}$ & $2.80(1.26)$ \\
\hline Age, years & $60.8(1.20)$ \\
\hline Male sex, $n(\%)$ & $2997(71.9)$ \\
\hline Smokers, $n(\%)$ & $1321(31.7)$ \\
\hline Body mass index, $\mathrm{kg} / \mathrm{m}^{2}$ & $26.5(1.16)$ \\
\hline \multicolumn{2}{|l|}{ Lipid parameters } \\
\hline Apolipoprotein B, g/L & $0.87(1.31)$ \\
\hline Apolipoprotein A1, g/L & $1.29(1.23)$ \\
\hline Triglycerides, $\mathrm{mmol} / \mathrm{L}$ & $1.54(1.67)$ \\
\hline \multicolumn{2}{|l|}{ Homocysteine metabolism, $\mu \mathrm{mol} / \mathrm{L}$} \\
\hline Methionine & $27.0(1.30)$ \\
\hline Total homocysteine & $10.7(1.38)$ \\
\hline Cystathionine & $0.28(1.81)$ \\
\hline Total cysteine & $290(1.14)$ \\
\hline Serine & $95.9(1.26)$ \\
\hline Glycine & $211(1.29)$ \\
\hline \multicolumn{2}{|l|}{ Inflammation } \\
\hline C-reactive protein, $\mathrm{mg} / \mathrm{mL}$ & $3.64(2.43)$ \\
\hline Uric acid, $\mu \mathrm{mol} / \mathrm{L}$ & $347(1.28)$ \\
\hline Neopterin, nmol/L & $8.57(1.47)$ \\
\hline Fibrinogen, $g / L$ & $3.61(1.21)$ \\
\hline KTR & $2.43(1.37)$ \\
\hline PAr & $0.51(1.58)$ \\
\hline \multicolumn{2}{|l|}{ Extent of CVD } \\
\hline $1-3$ stenotic vessels, $n(\%)$ & $3120(74.9)$ \\
\hline Previous acute myocardial infarction, $n(\%)$ & $1680(40.3)$ \\
\hline Ejection fraction $<60 \%, n(\%)$ & $3277(78.7)$ \\
\hline \multicolumn{2}{|l|}{ Kidney function } \\
\hline Creatinine, $\mu \mathrm{mol} / \mathrm{L}$ & $90.2(1.22)$ \\
\hline
\end{tabular}

Baseline characteristics of the total population. Continuous variables are presented as geometric means and geometric standard deviations. Categorical variables are presented as count and per cent

BMI was $26.5(1.16) \mathrm{kg} / \mathrm{m}^{2}$ and creatinine was $90.2(1.22)$ $\mu \mathrm{mol} / \mathrm{L}$. A total of $25.9 \%$ were smokers, whereas $74.8 \% \mathrm{had}$ significant coronary stenosis at baseline angiography. For the 1962 patients that completed the FFQ, mean (SD) energy intake was 2073 (694) kcal whereas vitamin A intake was 945 (606) RAE/1000 kcal/day.

\section{Biomarkers associated with retinol in the total population}

All analyses are presented in Fig. 1. Regression coefficients and their confidence intervals are given in Table 3. The strongest associations were found for serum creatinine, uric acid, triglycerides and plasma total cysteine, all of which were positively associated with serum retinol. Other positively associated biomarkers included plasma neopterin, plasma total homocysteine and serum apolipoprotein A1. Negatively associated biomarkers included CRP and plasma serine. Because 
Table 2 Baseline nutrient and food intake

\begin{tabular}{lc}
\hline Nutrients, E $\%$ & Mean (SD) \\
\hline Vitamin A, RAE/1000 kcal & $945(606)$ \\
Protein & $16.7(2.55)$ \\
Carbohydrate & $48.9(6.46)$ \\
Total fat & $31.9(5.61)$ \\
PUFA & $7.21(1.98)$ \\
MUFA & $10.3(2.03)$ \\
SFA & $11.8(2.65)$ \\
Alcohol & $2.06(3.16)$ \\
Foods, g/1000 kcal & \\
Meat & $54.8(23.4)$ \\
Vegetables & $105(80.9)$ \\
Fruits and berries & $124(86.1)$ \\
Eggs & $8.38(6.30)$ \\
Dairy & $154(112)$ \\
Fish & $53.7(28.8)$ \\
\hline
\end{tabular}

Baseline mean and standard deviation intake of nutrients and food groups

serum creatinine is used as a marker of kidney function, which may confound associations between biomarkers and serum retinol in the circulation, additional models were created and adjusted for serum creatinine. The results remained particularly for plasma total cysteine (standardized $\beta=0.17,95 \% \mathrm{CI}$ : $0.13,0.20, p<0.001$ ), serum uric acid (standardized $\beta=0.20$, 95\% CI: $0.17,0.24, p<0.001)$ and plasma serine (standardized $\beta=-0.11,95 \% \mathrm{CI}:-0.14,-0.07)$ and serum retinol, whereas the remaining associations were severely attenuated (data not shown).

We evaluated the linearity of the associations by fitting GAM-curves for the associations of serum creatinine, uric acid, plasma total cysteine and serine with serum retinol as shown in Fig. 2. All associations appeared to be linear.

To assess the fraction of variance explained by all associated biomarkers after Bonferroni adjustment, we included age, sex, serum creatinine, total cholesterol, apolipoprotein $\mathrm{A} 1$ and $\mathrm{B}$, triglycerides, uric acid and CRP, and plasma total homocysteine, cystathionine, total cysteine, serine, KTR, PAr, fibrinogen and neopterin in a multivariate regression model and calculated the adjusted $R^{2}$. The total proportion of variance explained was $33 \%$, and the predicted vs. observed values of log-transformed retinol based on this model are illustrated in Fig. 3.

\section{Associations between dietary intakes and serum retinol}

In total, 1962 patients completed the FFQ, and associations of dietary factors and retinol in serum are presented in Table 4. A weak, positive association was observed for
Associations of biomarkers with serum retinol Total population

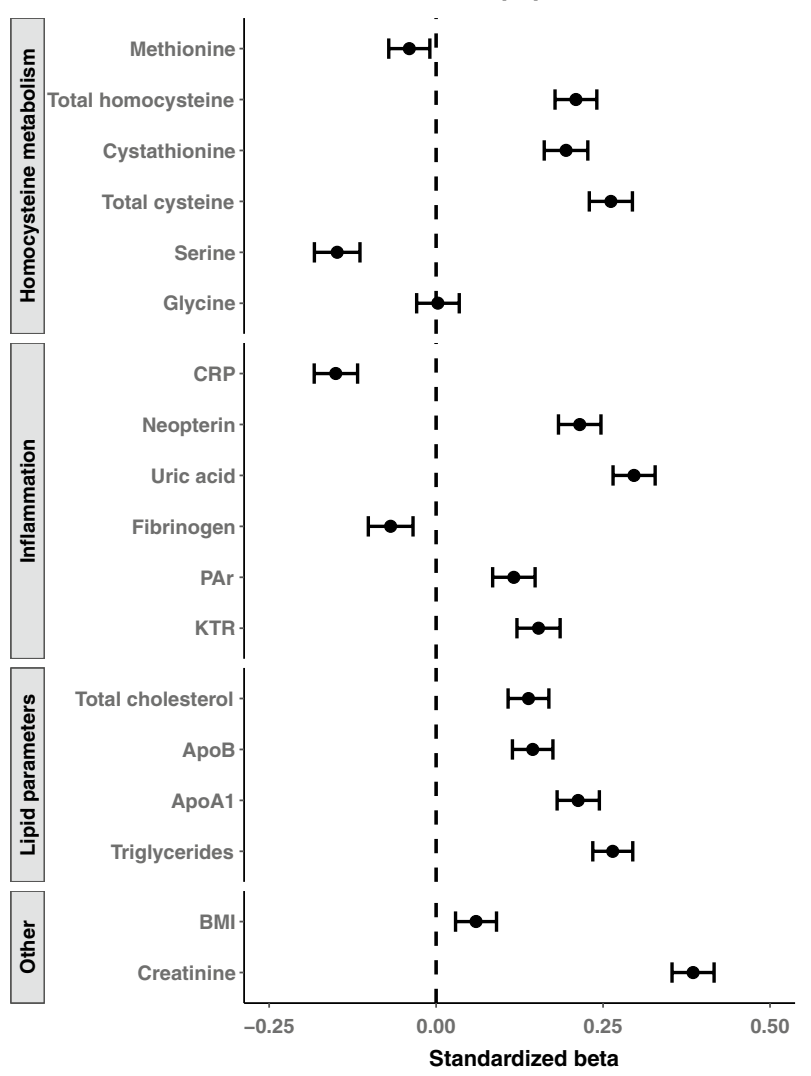

Fig. 1 Forest plot of predictors of serum retinol. The standardized $\beta$ and corresponding confidence intervals were derived from linear regression models adjusted for age and sex. CRP C-reactive protein, apo apolipoprotein, $K T R$ kynurenine to tryptophan ratio, $P A r$ pyridoxic acid to pyridoxal + pyridoxal-5-phosphate ratio, $B M I$ body mass index

meat and vegetable intake with serum retinol, whereas no particular associations were observed for other dietary variables including energy-adjusted RAE intake.

\section{Factors associated with retinol in patients with low and high concentrations}

Because of the substantial range in serum concentrations of retinol $(1.02-7.65 \mu \mathrm{mol} / \mathrm{L})$ we explored potential predictors, separately in patients in the lower and higher ranges of serum retinol. Results according to serum retinol tertiles are presented in Figs. 4 and 5. Results from the 1st and 3 rd tertile (retinol $<2.57$ and $>3.08 \mu \mathrm{mol} / \mathrm{L}$, respectively) showed generally the same, but slightly weaker associations as for the total population. Associations for serum creatinine, plasma total cysteine and serum uric acid remained prominent in the 1 st and 3rd tertiles. The associations for dietary 
Table 3 Regression coefficients and confidence intervals for biomarkers associated with retinol
Standardized $\beta\left(95 \%\right.$ CI) $\quad \beta$ per $10 \%$ increase (95\% CI) $\quad p$ value $\quad$ Adjusted $R^{2}(\%)$

\begin{tabular}{lllll}
\hline Lipid parameters & & & & \\
Total cholesterol & $0.14(0.11,0.17)$ & $1.47(1.15,1.8)$ & $<0.001$ & 2.17 \\
Apolipoprotein B & $0.14(0.11,0.17)$ & $1.37(1.04,1.51)$ & $<0.001$ & 2.36 \\
Apolipoprotein A1 & $0.21(0.18,0.24)$ & $2.44(2.12,2.81)$ & $<0.001$ & 4.36 \\
Triglycerides & $0.26(0.23,0.29)$ & $1.22(1.10,1.32)$ & $<0.001$ & 7.08 \\
Homocysteine metabolism & & & & \\
Methionine & $-0.04(-0.07,-0.01)$ & $-0.36(-0.62,-0.11)$ & 0.007 & 0.44 \\
Total homocysteine & $0.21(0.18,0.24)$ & $1.52(1.29,1.75)$ & $<0.001$ & 4.29 \\
Cystathionine & $0.19(0.16,0.23)$ & $0.76(0.21,0.52)$ & $<0.001$ & 3.80 \\
Total cysteine & $0.26(0.23,0.29)$ & $4.81(4.21,5.32)$ & $<0.001$ & 7.11 \\
Serine & $-0.15(-0.18,-0.11)$ & $-1.52(-1.88,-1.17)$ & $<0.001$ & 2.17 \\
Glycine & $0.00(-0.03,0.30)$ & $0.03(-0.27,0.31)$ & 0.823 & 0.30 \\
Inflammation & & & & \\
C-reactive protein & $-0.15(-0.18,-0.12)$ & $-0.41(-0.49,-0.32)$ & $<0.001$ & 2.50 \\
Uric acid & $0.30(0.26,0.33)$ & $2.81(2.52,3.23)$ & $<0.001$ & 9.71 \\
Neopterin & $0.22(0.18,0.25)$ & $1.43(1.21,1.62)$ & $<0.001$ & 4.34 \\
PAr & $0.12(0.08,0.15)$ & $0.60(0.43,0.76)$ & $<0.001$ & 1.53 \\
KTR & $0.15(0.12,0.19)$ & $1.14(0.90,1.38)$ & $<0.001$ & 2.35 \\
Fibrinogen & $-0.07(-0.10,-0.04)$ & $-0.83(-1.25,-0.42)$ & $<0.001$ & 0.70 \\
Body mass & & & & \\
Body mass index & $0.06(0.029,0.09)$ & $0.97(0.47,1.47)$ & 0.013 & 0.60 \\
Kidney function & & & & \\
Creatinine & $0.38(0.35,0.42)$ & $4.51(4.19,4.93)$ & $<0.001$ & 14.5
\end{tabular}

Regression coefficients for various predictors. All models were adjusted for age and sex. Coefficients represent the percentage change in retinol per $10 \%$ increase in the predictor and the adjusted $R^{2}$ represents the predictive power of the models

$P A r$ 4-pyridoxic acid/pyridoxal + pyridoxal-5-phophate ratio, KTR kynurenine/tryptophan ratio intakes with serum retinol were essentially similar for the total population (data not shown).

\section{Discussion}

\section{Principal findings}

Serum retinol has generally been considered to be under tight homeostatic control [15], and we have previously shown that retinol in serum of patients hospitalised for suspected coronary artery disease may range beyond what has been observed in other cohorts [4-9]. Factors associated with this variation have not been elucidated to a meaningful extent in CVD patients. In this exploratory study, we report observed associations for circulating and dietary factors with serum retinol in a large cohort of patients with suspected coronary artery disease. The most prominent associations were observed for creatinine, triglycerides, uric acid, serine and the sulphur amino acid cysteine. When we adjusted for serum creatinine, several of the associations were attenuated, whereas those of total cysteine and uric acid with serum retinol remained. Other positively associated biomarkers included plasma neopterin, but this association was attenuated after adjustment for creatinine. With the exception of meat and vegetable consumption, we found no particular associations between dietary intakes and serum retinol.

\section{Serum creatinine and retinol}

We observed a positive association between serum creatinine, a marker of kidney function, and serum retinol. This is in line with previous findings showing that retinol in serum increases in chronic kidney disease $[16,31]$ and that estimated glomerular filtration rate is an important determinant of retinol in an elderly population [32]. One case-control study found that serum retinol was positively associated with hypertension, and the authors speculate that this effect might have been mediated by kidney dysfunction [33]. However, because the RBP4-retinol-transthyretin complex is too large to be filtered, the kidneys are not considered to be an important route of retinol excretion [1]. The association between serum creatinine and retinol may thus be affected by other factors, and not increased renal retention. One study 


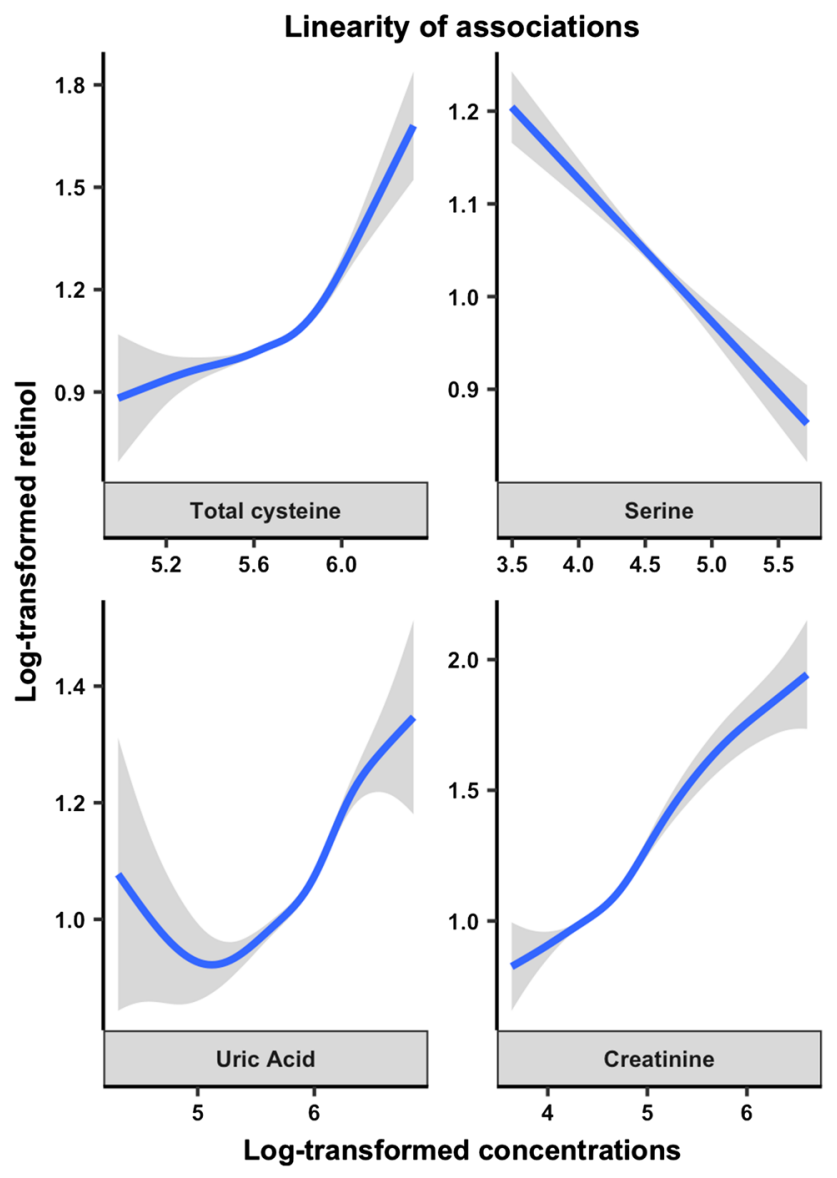

Fig. 2 Generalized additive model plots of the age and sex-adjusted linear association between selected predictors and log-transformed serum retinol

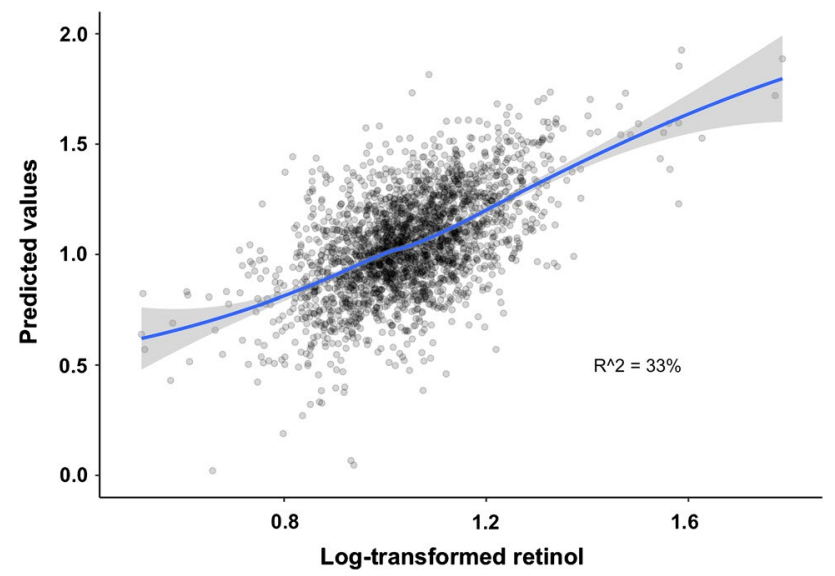

Fig. 3 Observed vs. predicted values of log-transformed serum retinol derived from a linear regression model including age, sex, total cysteine, uric acid, creatinine, neopterin, total cholesterol, apolipoprotein $\mathrm{A} 1$ and $\mathrm{B}$, triglycerides, total homocysteine and cystathionine, fibrinogen, pyridoxic acid to pyridoxal+ pyridoxal-5-phosphate ratio and kynurenine to tryptophan ratio suggests that elevated retinol in kidney dysfunction is due to disrupted signalling pathways that increase retinol release from liver storage when kidney function is compromised [16], indicating that metabolic alterations may affect vitamin A homeostasis with unknown consequences in patients with CVD.

\section{Plasma cysteine, serine and serum retinol}

To our knowledge, this is the first study demonstrating associations of plasma total cysteine and serine with serum retinol. In metabolism, serine is produced from glycolysis, serve as a precursor for glycine [34], and may condense with homocysteine to produce cystathionine and ultimately cysteine in transsulfuration $[35,36]$. In observational studies, plasma serine and total cysteine were inversely and positively associated to components of the metabolic syndrome, respectively [37-40]. Because there is little literature available on the possible relationship between cysteine and serine with retinol, it is difficult to interpret the direction of the observed associations in the present study, but some evidence from other populations with lifestyle diseases suggest that retinol may affect the metabolism of these amino acids. Notably, higher circulating concentrations of retinol bound to RBP4 may be associated with dysregulated glucose metabolism [12] which can impact serine production from glycolysis and partly explain the observed inverse association between serine and retinol. Furthermore, animal models have demonstrated that enzymes involved in homocysteine and cysteine metabolism can be induced by RA administration [41-43]. Interestingly, both serine-as a glycine precursor-and cysteine are central to the hepatic formation of glutathione $[35,36,44]$ a major antioxidant of which plasma concentrations can be low in subjects with obesity and CVD $[45,46]$. Whether the possible effects of retinol on serine and cysteine influence glutathione status is not known, and future studies should thus seek to address whether elevated cysteine and reduced serine in lifestyle disease and CVD (1) reflect reduced glutathione synthesis and (2) whether this effect is mediated by the bioactive RA.

\section{Inflammatory markers and serum retinol}

Studies on the relationship between inflammation and vitamin A are extensive [3, 17, 47]. Markers of the acute phase response, such as CRP, are inversely related to retinol [17]. It is generally accepted that systemic inflammation may contribute to increased sequestration of retinol in tissues and subsequently to reduced serum concentrations. In line with this notion, we observed an inverse association between CRP and retinol. In contrast, other inflammatory markers associated with CVD risk, such as uric acid [48], were positively associated with serum retinol. This particular finding reflects 
Table 4 Regression coefficients and confidence intervals for dietary predictors of serum retinol

\begin{tabular}{|c|c|c|c|c|}
\hline Macronutrients & Standardized $\beta(95 \% \mathrm{CI})$ & $\beta$ per $E \%(95 \% \mathrm{CI})$ & $p$ value & Adjusted $R^{2}(\%)$ \\
\hline Protein & $0.063(0.02,0.11)$ & $0.52(0.16,0.89)$ & 0.005 & 1.10 \\
\hline Carbohydrate & $-0.062(-0.11,-0.018)$ & $-0.21(-0.36,-0.07)$ & 0.004 & 1.18 \\
\hline Total fat & $0.002(-0.041,0.045)$ & $-0.02(-0.19,0.14)$ & 0.77 & 0.70 \\
\hline PUFA & $-8 \mathrm{e}-04(-0.045,0.043)$ & $-0.11(-0.58,0.36)$ & 0.65 & 0.79 \\
\hline MUFA & $0.022(-0.022,0.065)$ & $0.15(-0.31,0.61)$ & 0.53 & 0.83 \\
\hline SFA & $-0.0053(-0.048,0.038)$ & $-0.12(-0.47,0.22)$ & 0.48 & 0.81 \\
\hline Alcohol & $0.077(0.026,0.13)$ & $0.47(0.15,0.79)$ & 0.004 & 1.01 \\
\hline Micronutrient & & $\beta$ per 200 RAE/1000 kcal $(95 \%$ CI $)$ & & \\
\hline Vitamin A & $0.017(-0.029,0.062)$ & $0.29(-0.03,3.27)$ & 0.09 & 0.80 \\
\hline Foods & & $\beta$ per 50 g/1000 kcal $(95 \%$ CI $)$ & & \\
\hline Meat & $0.076(0.032,0.12)$ & $3.60(1.54,5.66)$ & $<0.001$ & 1.30 \\
\hline Vegetables & $0.04(-0.0033,0.084)$ & $0.91(0.33,1.50)$ & 0.002 & 1.15 \\
\hline Fruits and berries & $0.005(-0.039,0.049)$ & $0.13(-0.41,0.68)$ & 0.63 & 0.70 \\
\hline Eggs & $0.012(-0.032,0.056)$ & $0.55(-7.13,8.25)$ & 0.89 & 0.70 \\
\hline Dairy & $0.048(0.0048,0.092)$ & $0.41(-0.01,0.82)$ & 0.06 & 0.91 \\
\hline Fish & $-0.0068(-0.051,0.037)$ & $-0.02(-1.67,1.61)$ & 0.97 & 0.72 \\
\hline
\end{tabular}

Regression coefficients for various dietary predictors. All models were adjusted for age, sex and energy intake. Coefficients represent the percentage change in vitamin A per $10 \%$ increase in the predictor and the adjusted $R^{2}$ represents the predictive power of the models

those of others, which have shown a positive association between uric acid and retinol in large and healthy cohorts $[49,50]$. There may be several potential unmeasured factors that affect this association, but interestingly, the enzyme that produce uric acid-xanthine oxidase-has been linked to endothelial dysfunction in atherosclerosis [51] and can also catalyse the formation of RA [52]. Further, neopterin, a marker of the pro-atherogenic $\mathrm{T}_{\mathrm{h}} 1$ cell-mediated monocyte activation that has been linked CVD risk [53, 54] was positively associated with retinol in the present investigation. It is not known whether neopterin itself affects retinol concentrations, however, in vitro studies show that RA administered in physiological doses activate $T_{h} 1$ cells [47] which in turn can contribute to proliferation of monocytes into macrophages and increased neopterin concentrations [53]. Our findings indicate a potential interplay between inflammatory processes in atherosclerosis and retinol and should be addressed in future studies. Specifically, the uptake and metabolism of retinol and activity of RA in immune cells during inflammatory processes specific to atherosclerosis would provide insight in this context.

\section{Diet and serum retinol}

The observed associations for the dietary predictors were weak, which is not unexpected considering the relatively stable concentrations of circulating retinol $[55,56]$. Although the existing evidence for the association for meat intake and retinol is somewhat conflicting $[57,58]$ we did observe positive association between meat intake and serum retinol.
Meat (in particular processed meat) intake should be limited in the context of CVD prevention [59] and taken together with the other results of the present investigation indicate that high serum concentrations of retinol at least in part are explained by factors related to an unfavourable risk profile in these patients. We cannot exclude the possibility that the bias present in dietary assessment tools obscured the true associations.

\section{Strengths and limitations}

The major strength of our study was the large, well-characterized cohort including more than 4000 patients, the majority with angiographically verified coronary artery disease, which provided a solid basis for the evaluation of biomarkers and dietary factors associated with serum retinol. However, our findings cannot be generalized beyond the study population, because serum concentrations of retinol appear to be elevated in patients with CVD compared to a presumably healthy population residing in the same geographical area [60]. Further limitations include the cross-sectional design, which complicates the interpretation of the direction of the associations. Moreover, at this point the clinical implications are limited because many of the results presented here are novel, and relevance is difficult to establish until results are replicated in other cohorts. The interpretation of the associations between total cysteine and uric acid with retinol was particularly complicated because it is unclear whether cysteine and uric acid affect retinol or vice versa. 


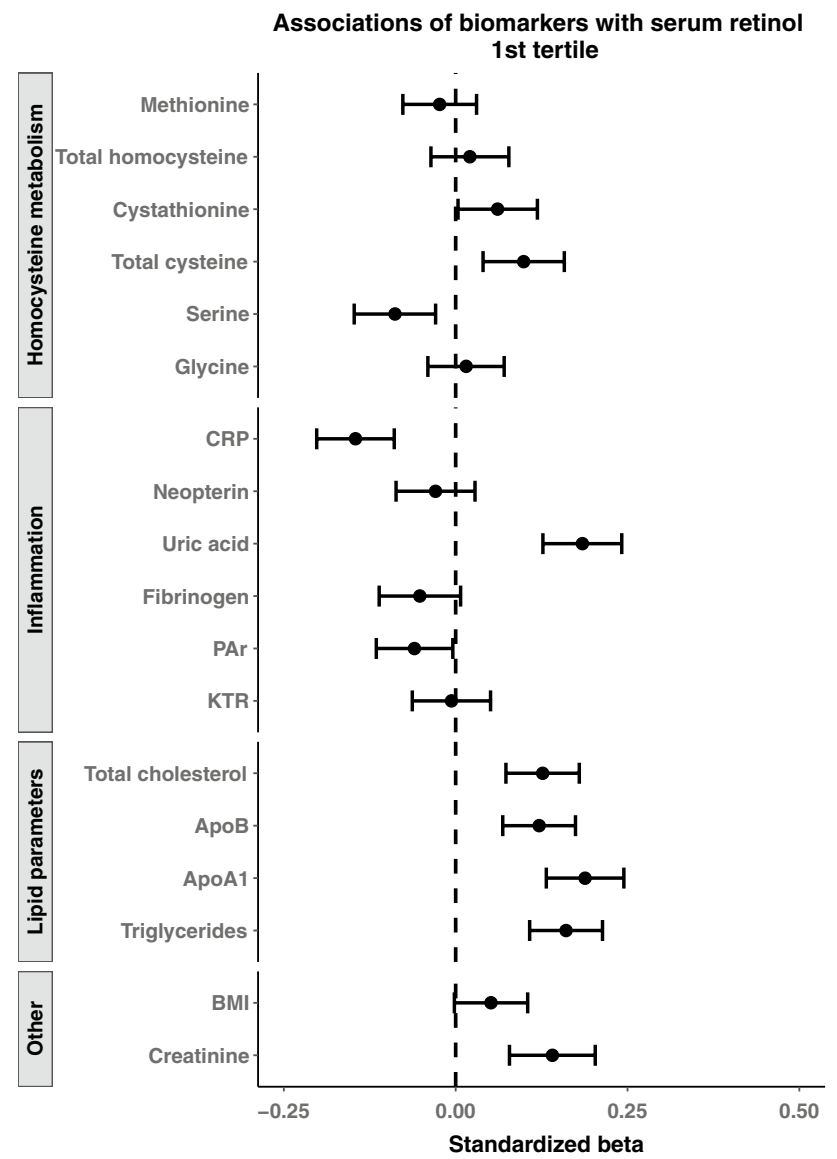

Fig. 4 Forest plot illustrating predictors of serum retinol in the lower retinol tertile. The standardized $\beta$ and corresponding confidence intervals were derived from linear regression models adjusted for age and sex. CRP C-reactive protein, apo apolipoprotein, KTR kynurenine to tryptophan ratio, $P A r$ pyridoxic acid to pyridoxal + pyridoxal5-phosphate ratio, $B M I$ body mass index

It should be noted that the proportion of variance explained by the models was generally low. Overall, the adjusted $R^{2}$ varied from 4 to $\sim 15 \%$, for the models, whereas a multivariate model including the most strongly associated biomarkers explained about $33 \%$ of the total variation in serum retinol. Although some of the unmeasured variations may be attributed to genetics $[61,62]$, we emphasize that very little is currently known about factors affecting retinol in the circulation and that a continued effort should be undertaken to further explore this particular knowledge gap.

\section{Conclusion}

Biomarkers associated with retinol in patients with established CVD include metabolites that are linked to metabolic disease, kidney function, and inflammation. Future
Associations of biomarkers with serum retinol 3rd tertile

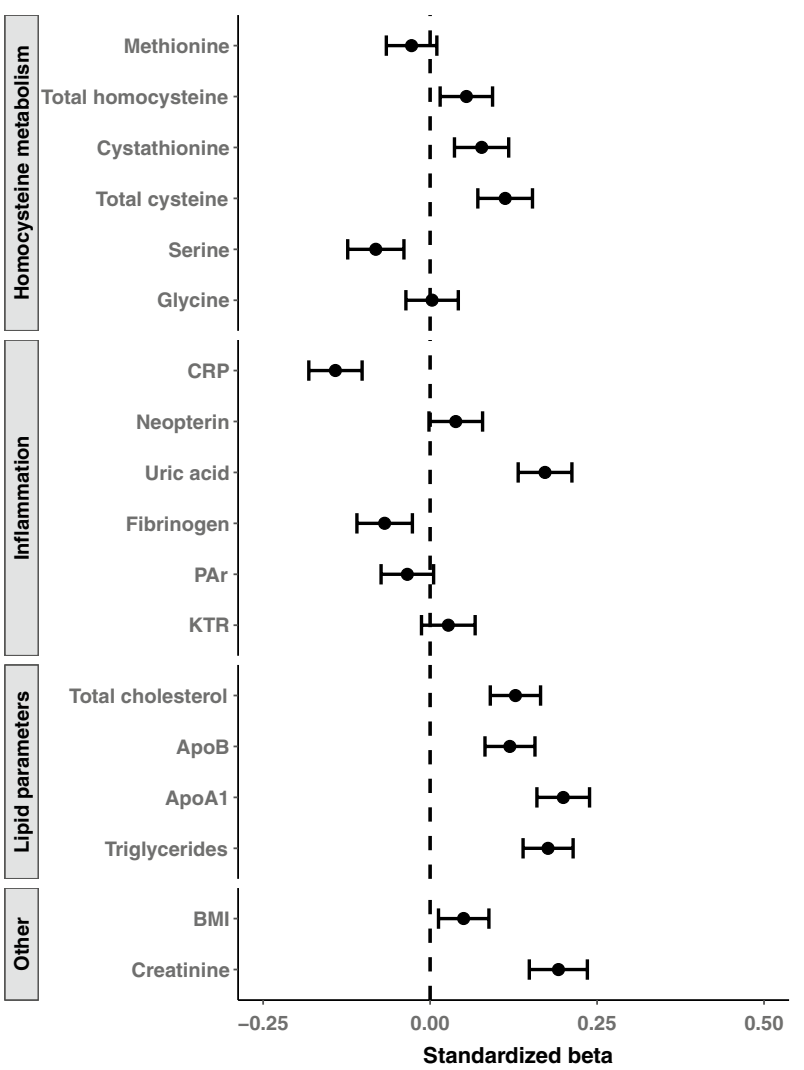

Fig. 5 Forest plot illustrating predictors of serum retinol in the upper retinol tertile. The standardized $\beta$ and corresponding confidence intervals were derived from linear regression models adjusted for age and sex. CRP C-reactive protein, apo apolipoprotein, KTR kynurenine to tryptophan ratio, $P A r$ pyridoxic acid to pyridoxal + pyridoxal5-phosphate ratio, $B M I$ body mass index

observational and experimental studies should assess the potential causal direction and the clinical relevance of these associations. Finally, it would be useful to assess these associations in healthy populations, to further uncover the role of retinol in health and disease.

Acknowledgements The authors would like to thank all study participants and study personnel for their invaluable contributions to this work. The study was funded by The Advanced Research Program and Research Council of Norway; the Department of Heart Disease at Haukeland University Hospital; the Norwegian Foundation for Health and Rehabilitation; the Norwegian Heart and Lung Patient Organization; the Norwegian Ministry of Health and Care Services; the Western Norway Regional Health Authority; and the Institute of Medical Biosciences, University of Oslo.

Funding This research was supported by Norges Forskningsråd, Haukeland Universitetssjukehus, EkstraStiftelsen Helse og Rehabilitering, Landsforeningen for Hjerte- og Lungesyke, Helse Vest Regionalt Helseføretak and Universitetet i Oslo. 


\section{Compliance with Ethical Standards}

Conflict of interest The authors declare that they have no conflicts of interest.

Open Access This article is distributed under the terms of the Creative Commons Attribution 4.0 International License (http://creativeco mmons.org/licenses/by/4.0/), which permits unrestricted use, distribution, and reproduction in any medium, provided you give appropriate credit to the original author(s) and the source, provide a link to the Creative Commons license, and indicate if changes were made.

\section{References}

1. Blomhoff R, Blomhoff HK (2006) Overview of retinoid metabolism and function. J Neurobiol 66(7):606-630. https://doi. org/10.1002/neu.20242

2. Chen W, Chen G (2014) The roles of vitamin A in the regulation of carbohydrate, lipid, and protein metabolism. J Clin Med 3(2):453-479. https://doi.org/10.3390/jcm3020453

3. Patel S, Vajdy M (2015) Induction of cellular and molecular immunomodulatory pathways by vitamin A and flavonoids. Expert Opin Biol Ther 15(10):1411-1428. https://doi.org/10.1517/14712 598.2015.1066331

4. Olsen T, Vinknes KJ, Svingen GFT, Pedersen ER, Tell GS, Blomhoff R, Drevon CA, Ueland PM, Midttun O, Refsum H, Nygard OK (2017) Cardiovascular disease risk associated with serum apolipoprotein B is modified by serum vitamin A. Atherosclerosis. https://doi.org/10.1016/j.atherosclerosis.2017.07.020

5. Olsen T, Vinknes KJ, Svingen GF, Pedersen ER, Dhar I, Tell GS, Blomhoff R, Ueland PM, Midttun O, Refsum H, Nygard OK (2018) The risk association of plasma total homocysteine with acute myocardial infarction is modified by serum vitamin A. Eur J Prev Cardiol 25(15):1612-1620. https://doi.org/10.1177/20474 87318788587

6. Ballew C, Bowman BA, Sowell AL, Gillespie C (2001) Serum retinol distributions in residents of the United States: third National Health and Nutrition Examination Survey, 19881994. Am J Clin Nutr 73(3):586-593. https://doi.org/10.1093/ ajcn/73.3.586

7. Michaelsson K, Lithell H, Vessby B, Melhus H (2003) Serum retinol levels and the risk of fracture. N Engl J Med 348(4):287-294. https://doi.org/10.1056/NEJMoa021171

8. Bakker MF, Peeters PH, Klaasen VM, Bueno-de-Mesquita HB, Jansen EH, Ros MM, Travier N, Olsen A, Tjonneland A, Overvad K, Rinaldi S, Romieu I, Brennan P, Boutron-Ruault MC, Perquier F, Cadeau C, Boeing H, Aleksandrova K, Kaaks R, Kuhn T, Trichopoulou A, Lagiou P, Trichopoulos D, Vineis P, Krogh V, Panico S, Masala G, Tumino R, Weiderpass E, Skeie G, Lund E, Quiros JR, Ardanaz E, Navarro C, Amiano P, Sanchez MJ, Buckland G, Ericson U, Sonestedt E, Johansson M, Sund M, Travis RC, Key TJ, Khaw KT, Wareham N, Riboli E, van Gils CH (2016) Plasma carotenoids, vitamin $\mathrm{C}$, tocopherols, and retinol and the risk of breast cancer in the European Prospective Investigation into Cancer and Nutrition cohort. Am J Clin Nutr 103(2):454-464. https://doi.org/10.3945/ajcn.114.101659

9. Stephensen CB, Gildengorin G (2000) Serum retinol, the acute phase response, and the apparent misclassification of vitamin A status in the third National Health and Nutrition Examination Survey. Am J Clin Nutr 72(5):1170-1178. https://doi.org/10.1093/ ajen/72.5.1170
10. Kanagasabai T, Alkhalaqi K, Churilla JR, Ardern CI (2018) The association between metabolic syndrome and serum concentrations of micronutrients, inflammation, and oxidative stress outside of the clinical reference ranges: a Cross-Sectional Study. Metab Syndr Relat Disord. https://doi.org/10.1089/met.2018.0080

11. Min KB, Min JY (2014) Relation of serum vitamin A levels to all-cause and cause-specific mortality among older adults in the NHANES III population. Nutr Metab Cardiovasc Dis 24(11):1197-1203. https://doi.org/10.1016/j.numecd.2014.06.004

12. Park SE, Park CY, Sweeney G (2015) Biomarkers of insulin sensitivity and insulin resistance: past, present and future. Crit Rev Clin Lab Sci 52(4):180-190. https://doi.org/10.3109/10408 363.2015.1023429

13. Mody N (2017) Alterations in vitamin A/retinoic acid homeostasis in diet-induced obesity and insulin resistance. Proc Nutr Soc 76(4):597-602. https://doi.org/10.1017/S0029665117001069

14. Liu Y, Zhong Y, Chen H, Wang D, Wang M, Ou JS, Xia M (2017) Retinol-binding protein-dependent cholesterol uptake regulates macrophage foam cell formation and promotes atherosclerosis. Circulation 135(14):1339-1354. https://doi.org/10.1161/CIRCU LATIONAHA.116.024503

15. Olson JA (1984) Serum levels of vitamin A and carotenoids as reflectors of nutritional status. J Natl Cancer Inst 73(6):1439-1444

16. Jing J, Isoherranen N, Robinson-Cohen C, Petrie I, Kestenbaum BR, Yeung CK (2016) Chronic kidney disease alters vitamin A homeostasis via effects on hepatic RBP4 protein expression and metabolic enzymes. Clin Transl Sci 9(4):207-215. https://doi. org/10.1111/cts. 12402

17. Rubin LP, Ross AC, Stephensen CB, Bohn T, Tanumihardjo SA (2017) Metabolic effects of inflammation on vitamin A and carotenoids in humans and animal models. Adv Nutr 8(2):197-212. https://doi.org/10.3945/an.116.014167

18. Svingen GF, Ueland PM, Pedersen EK, Schartum-Hansen H, Seifert R, Ebbing M, Loland KH, Tell GS, Nygard O (2013) Plasma dimethylglycine and risk of incident acute myocardial infarction in patients with stable angina pectoris. Arterioscler Thromb Vasc Biol 33(8):2041-2048. https://doi.org/10.1161/ATVBA HA.113.301714

19. Ebbing M, Bleie O, Ueland PM, Nordrehaug JE, Nilsen DW, Vollset SE, Refsum H, Pedersen EK, Nygard O (2008) Mortality and cardiovascular events in patients treated with homocysteinelowering B vitamins after coronary angiography: a randomized controlled trial. JAMA 300(7):795-804. https://doi.org/10.1001/ jama.300.7.795

20. Windelberg A, Arseth O, Kvalheim G, Ueland PM (2005) Automated assay for the determination of methylmalonic acid, total homocysteine, and related amino acids in human serum or plasma by means of methylchloroformate derivatization and gas chromatography-mass spectrometry. Clin Chem 51(11):2103-2109. https ://doi.org/10.1373/clinchem.2005.053835

21. Midttun O, McCann A, Aarseth O, Krokeide M, Kvalheim G, Meyer K, Ueland PM (2016) Combined measurement of 6 fatsoluble vitamins and 26 water-soluble functional vitamin markers and amino acids in $50 \mu \mathrm{L}$ of serum or plasma by high-throughput mass spectrometry. Anal Chem 88(21):10427-10436. https://doi. org/10.1021/acs.analchem.6b02325

22. Midttun O, Ueland PM (2011) Determination of vitamins A, D and $\mathrm{E}$ in a small volume of human plasma by a high-throughput method based on liquid chromatography/tandem mass spectrometry. Rapid Commun Mass Spectrom 25(14):1942-1948. https:// doi.org/10.1002/rcm.5073

23. Midttun O, Kvalheim G, Ueland PM (2013) High-throughput, low-volume, multianalyte quantification of plasma metabolites related to one-carbon metabolism using HPLC-MS/MS. Anal Bioanal Chem 405(6):2009-2017. https://doi.org/10.1007/s0021 6-012-6602-6 
24. Midttun O, Hustad S, Ueland PM (2009) Quantitative profiling of biomarkers related to B-vitamin status, tryptophan metabolism and inflammation in human plasma by liquid chromatography/tandem mass spectrometry. Rapid Commun Mass Spectrom 23(9):1371-1379. https://doi.org/10.1002/rcm.4013

25. Ulvik A, Midttun O, Pedersen ER, Eussen SJ, Nygard O, Ueland PM (2014) Evidence for increased catabolism of vitamin B-6 during systemic inflammation. Am J Clin Nutr 100(1):250-255. https ://doi.org/10.3945/ajcn.114.083196

26. Ueland PM, McCann A, Midttun O, Ulvik A (2017) Inflammation, vitamin B6 and related pathways. Mol Aspects Med 53:10-27. https://doi.org/10.1016/j.mam.2016.08.001

27. Mjelva OR, Svingen GFT, Pedersen EKR, Seifert R, Kvaloy JT, Midttun O, Ueland PM, Nordrehaug JE, Nygard O, Nilsen DWT (2018) Fibrinogen and neopterin is associated with future myocardial infarction and total mortality in patients with stable coronary artery disease. Thromb Haemost 118(4):778-790. https://doi.org/10.1055/s-0038-1629912

28. Nes M, Frost Andersen L, Solvoll K, Sandstad B, Hustvedt BE, Lovo A, Drevon CA (1992) Accuracy of a quantitative food frequency questionnaire applied in elderly Norwegian women. Eur J Clin Nutr 46(11):809-821

29. Hjartaker A, Andersen LF, Lund E (2007) Comparison of diet measures from a food-frequency questionnaire with measures from repeated $24 \mathrm{~h}$ dietary recalls. The Norwegian Women and Cancer Study. Public Health Nutr 10(10):1094-1103. https:// doi.org/10.1017/s1368980007702872

30. Andersen LF, Tomten H, Haggarty P, Lovo A, Hustvedt BE (2003) Validation of energy intake estimated from a food frequency questionnaire: a doubly labelled water study. Eur J Clin Nutr 57(2):279-284. https://doi.org/10.1038/sj.ejcn.1601519

31. Chen J, He J, Ogden LG, Batuman V, Whelton PK (2002) Relationship of serum antioxidant vitamins to serum creatinine in the US population. Am J Kidney Dis 39(3):460-468. https://doi. org/10.1053/ajkd.2002.31389

32. Granado-Lorencio F, Blanco-Navarro I, Perez-Sacristan B, Millan I, Donoso-Navarro E, Silvestre-Mardomingo RA (2013) Determinants of fat-soluble vitamin status in patients aged 65 years and over. Eur J Clin Nutr 67(12):1325-1327. https:// doi.org/10.1038/ejen.2013.198

33. Danquah I, Dobrucky CL, Frank LK, Henze A, Amoako YA, Bedu-Addo G, Raila J, Schulze MB, Mockenhaupt FP, Schweigert FJ (2015) Vitamin A: potential misclassification of vitamin A status among patients with type 2 diabetes and hypertension in urban Ghana. Am J Clin Nutr 102(1):207-214. https:// doi.org/10.3945/ajen.114.101345

34. Amelio I, Cutruzzola F, Antonov A, Agostini M, Melino G (2014) Serine and glycine metabolism in cancer. Trends Biochem Sci 39(4):191-198. https://doi.org/10.1016/j. tibs.2014.02.004

35. Brosnan JT, Brosnan ME (2006) The sulfur-containing amino acids: an overview. J Nutr 136(6 Suppl):1636S-1640S

36. Mosharov E, Cranford MR, Banerjee R (2000) The quantitatively important relationship between homocysteine metabolism and glutathione synthesis by the transsulfuration pathway and its regulation by redox changes. Biochemistry 39(42):13005-13011

37. Yamada C, Kondo M, Kishimoto N, Shibata T, Nagai Y, Imanishi T, Oroguchi T, Ishii N, Nishizaki Y (2015) Association between insulin resistance and plasma amino acid profile in non-diabetic Japanese subjects. J Diabetes Investig 6(4):408415. https://doi.org/10.1111/jdi.12323

38. Ntzouvani A, Nomikos T, Panagiotakos D, Fragopoulou E, Pitsavos C, McCann A, Ueland PM, Antonopoulou S (2017) Amino acid profile and metabolic syndrome in a male Mediterranean population: a cross-sectional study. Nutr Metab
Cardiovasc Dis 27(11):1021-1030. https://doi.org/10.1016/j. numecd.2017.07.006

39. Elshorbagy AK, Kozich V, Smith AD, Refsum H (2012) Cysteine and obesity: consistency of the evidence across epidemiologic, animal and cellular studies. Curr Opin Clin Nutr Metab Care 15(1):49-57. https://doi.org/10.1097/MCO.0b013e32834d199f

40. Elshorbagy AK, Valdivia-Garcia M, Refsum H, Butte N (2012) The association of cysteine with obesity, inflammatory cytokines and insulin resistance in Hispanic children and adolescents. PLoS One 7(9):e44166. https://doi.org/10.1371/journal.pone.0044166

41. Rowling MJ, McMullen MH, Schalinske KL (2002) Vitamin A and its derivatives induce hepatic glycine $N$-methyltransferase and hypomethylation of DNA in rats. J Nutr 132(3):365-369

42. Ozias MK, Schalinske KL (2003) All-trans-retinoic acid rapidly induces glycine $\mathrm{N}$-methyltransferase in a dose-dependent manner and reduces circulating methionine and homocysteine levels in rats. J Nutr 133(12):4090-4094

43. el Yaagoubi M, Hachad H, Leh H, Siest G, Wellman M (1995) $\gamma$-Glutamyltransferase expression during all-trans retinoic acidinduced differentiation of hematopoietic cell lines. FEBS Lett 369(2-3):183-186

44. Lu SC (2009) Regulation of glutathione synthesis. Mol Aspects Med 30(1-2):42-59. https://doi.org/10.1016/j.mam.2008.05.005

45. Giral P, Jacob N, Dourmap C, Hansel B, Carrie A, Bruckert E, Girerd X, Chapman MJ (2008) Elevated gamma-glutamyltransferase activity and perturbed thiol profile are associated with features of metabolic syndrome. Arterioscler Thromb Vasc Biol 28(3):587-593. https://doi.org/10.1161/ATVBAHA.107.157891

46. Shimizu H, Kiyohara Y, Kato I, Kitazono T, Tanizaki Y, Kubo M, Ueno H, Ibayashi S, Fujishima M, Iida M (2004) Relationship between plasma glutathione levels and cardiovascular disease in a defined population: the Hisayama study. Stroke 35(9):2072-2077. https://doi.org/10.1161/01.STR.0000138022.86509.2d

47. Bono, Tejon G, Flores-Santibanez F, Fernandez D, Rosemblatt M, Sauma D (2016) Retinoic acid as a modulator of T cell immunity. Nutrients. https://doi.org/10.3390/nu8060349

48. Kushiyama A, Nakatsu Y, Matsunaga Y, Yamamotoya T, Mori K, Ueda K, Inoue Y, Sakoda H, Fujishiro M, Ono H, Asano T (2016) Role of uric acid metabolism-related inflammation in the pathogenesis of metabolic syndrome components such as atherosclerosis and nonalcoholic steatohepatitis. Mediat Inflamm 2016:8603164. https://doi.org/10.1155/2016/8603164

49. Ford ES, Choi HK (2013) Associations between concentrations of uric acid with concentrations of vitamin A and beta-carotene among adults in the United States. Nutr Res 33(12):995-1002. https://doi.org/10.1016/j.nutres.2013.08.008

50. Choi WJ, Ford ES, Curhan G, Rankin JI, Choi HK (2012) Independent association of serum retinol and beta-carotene levels with hyperuricemia: a national population study. Arthritis Care Res (Hoboken) 64(3):389-396. https://doi.org/10.1002/acr.20692

51. George J, Struthers AD (2009) Role of urate, xanthine oxidase and the effects of allopurinol in vascular oxidative stress. Vasc Health Risk Manag 5(1):265-272

52. Mawson AR (1984) Hypervitaminosis A toxicity and gout. Lancet 1(8387):1181

53. Fuchs D, Avanzas P, Arroyo-Espliguero R, Jenny M, Consuegra-Sanchez L, Kaski JC (2009) The role of neopterin in atherogenesis and cardiovascular risk assessment. Curr Med Chem 16(35):4644-4653

54. Taleb S (2016) Inflammation in atherosclerosis. Arch Cardiovasc Dis 109(12):708-715. https://doi.org/10.1016/j.acvd.2016.04.002

55. Hodge AM, Simpson JA, Fridman M, Rowley K, English DR, Giles GG, Su Q, O'Dea K (2009) Evaluation of an FFQ for assessment of antioxidant intake using plasma biomarkers in an ethnically diverse population. Public Health Nutr 12(12):2438-2447. https://doi.org/10.1017/s1368980009005539 
56. Jarvinen R, Knekt P, Seppanen R, Heinonen M, Aaran RK (1993) Dietary determinants of serum beta-carotene and serum retinol. Eur J Clin Nutr 47(1):31-41

57. Li D, Sinclair AJ, Mann NJ, Turner A, Ball MJ (2000) Selected micronutrient intake and status in men with differing meat intakes, vegetarians and vegans. Asia Pac J Clin Nutr 9(1):18-23

58. Barbosa FP, Luna RC, Monteiro MG, Asciutti LS, de Oliveira RS, Diniz Ada S, Lima RT, Benigna MJ, de Moraes RM, Costa MJ, Goncalves Mda C (2013) Relationship between hemoglobin, serum retinol and habitual meat consumption in the elderly: a population-based study. Arch Gerontol Geriatr 57(1):60-65. https ://doi.org/10.1016/j.archger.2013.01.004

59. Piepoli MF, Hoes AW, Agewall S, Albus C, Brotons C, Catapano AL, Cooney MT, Corra U, Cosyns B, Deaton C, Graham I, Hall, Hobbs FDR, Lochen ML, Lollgen H, Marques-Vidal P, Perk J, Prescott E, Redon J, Richter DJ, Sattar N, Smulders Y, Tiberi M, van der Worp HB, van Dis I, Verschuren WMM, Binno S, Group ESCSD (2016) European Guidelines on cardiovascular disease prevention in clinical practice: the Sixth Joint Task Force of the European Society of Cardiology and Other Societies on Cardiovascular Disease Prevention in Clinical Practice (constituted by representatives of 10 societies and by invited experts)Developed with the special contribution of the European Association for Cardiovascular Prevention and Rehabilitation (EACPR). Eur Heart J 37(29):2315-2381. https://doi.org/10.1093/eurheartj/ehw106

60. Holvik K, Ahmed LA, Forsmo S, Gjesdal CG, Grimnes G, Samuelsen SO, Schei B, Blomhoff R, Tell GS, Meyer HE (2015) No increase in risk of hip fracture at high serum retinol concentrations in community-dwelling older Norwegians: the Norwegian Epidemiologic Osteoporosis Studies. Am J Clin Nutr. https://doi. org/10.3945/ajen.115.110528

61. Mondul AM, Yu K, Wheeler W, Zhang H, Weinstein SJ, Major JM, Cornelis MC, Mannisto S, Hazra A, Hsing AW, Jacobs KB, Eliassen H, Tanaka T, Reding DJ, Hendrickson S, Ferrucci L, Virtamo J, Hunter DJ, Chanock SJ, Kraft P, Albanes D (2011) Genome-wide association study of circulating retinol levels. Hum Mol Genet 20(23):4724-4731. https://doi.org/10.1093/hmg/ddr38 7

62. Gueguen S, Leroy P, Gueguen R, Siest G, Visvikis S, Herbeth B (2005) Genetic and environmental contributions to serum retinol and alpha-tocopherol concentrations: the Stanislas Family Study. Am J Clin Nutr 81(5):1034-1044 